\title{
A COMPARATIVE BETWEEN THE SUPPLY AND ENERGY NEEDS OF HOSPITALIZED PATIENTS UNDER ENTERAL NUTRITIONAL THERAPY
}

\author{
Aline Gamarra Taborda ${ }^{1}$, Alessandra Campani Pizzato²
}

\begin{abstract}
Introduction: Patients who are at risk of malnutrition are potential candidates for the use of enteral nutritional therapy (ENT), since it allows a more effective control of the patient's nutrition. When oral food intake is impossible or insufficient, enteral nutrition is the most appropriate physiological option aiming at the maintenance of gastrointestinal trophism. Studies show us that the protein-caloric needs of the hospitalized patients are seldom reached in the feeding tube supply, staying routinely between $70 \%$ and $80 \%$ of their needs.
\end{abstract}

Methods: A descriptive study was conducted based on secondary data collected by the Multidisciplinary Team of Nutritional Therapy of a university hospital in Brazil to compare the caloric intake received by the hospitalized patients when in enteral nutritional therapy with their real needs.

Results: A total of 43 adult inpatients who were in exclusive enteral nutrition were assessed. It was observed that the mean caloric intake received by the patients was $1,767 \pm 271 \mathrm{kcal} / \mathrm{day}$, reaching $94 \%$ of the estimated caloric needs, which were $321 \mathrm{kcal} / \mathrm{day}$. In relation to the nutritional status of the analyzed patients, it was found that $38 \%$ were at nutritional risk.

Conclusion: The creation of protocols of nutritional support is of great importance to guide professionals in the prescription of ENT, aiming to improve the nutritional intake offered to hospitalized patients.

Keywords: Enteral nutrition; malnutrition; caloric intake; caloric needs

Nutritional needs vary from individual to individual, and should be based on factors that reflect the current status of each one, considering aspects ranging from their body composition to their pathology. The oral route is a priority for food supply; however, once oral food intake is impossible or insufficient, another form of nutrition should be sought in order to prevent malnutrition, such as enteral nutrition and/or parenteral nutrition, each of which has its indications and implications ${ }^{1}$.

Enteral nutrition is the most indicated physiological option mainly due to the maintenance of gastrointestinal trophism and, consequently, the functional integrity of the digestive tract ${ }^{2,3}$. It is known that the lack of use of the gastrointestinal tract causes a reduction in villus height after two weeks and may lead to mucosal atrophy ${ }^{1,4}$.

Enteral nutritional therapy is used to restore or maintain the nutritional status of patients and should be used when the patient has a functioning gastrointestinal tract. It is noteworthy that some situations contraindicate enteral nutrition, such as paralytic ileus, high-output fistulae in GIT, severe acute pancreatitis, and severe gastrointestinal hemorrhage ${ }^{3,5}$. Enteral nutrition has several advantages that prioritize its use over parenteral nutrition, such as reduced risk of infections in traumatized, burned, and postoperative patients ${ }^{6,7}$.

In enteral nutritional therapy, there are different access routes to nourish the patient. The nasogastric and nasoenteric routes are the most frequently used in hospitals. Another option of access route for nutritional therapy is ostomy, being indicated for patients who require enteral nutrition for longer
Clin Biomed Res. 2017;37(3):157-162

1 Instituto do Aparelho Digestivo (IAD). Porto Alegre, RS, Brazil.

2 Faculdade de Nutrição, Pontifícia Universidade Católica do Rio Grande do Sul (PUCRS). Porto Alegre, RS, Brazil.

Corresponding author: Aline Gamarra Taborda alinegamarrat@hotmail.com Instituto do Aparelho Digestivo (IAD) Av. Cristóvão Colombo, 3060. 90560-002, Porto Alegre, RS, Brazil. 
periods. Examples of ostomies include gastrostomy and jejunostomy, both indicated for patients requiring long-term enteral feeding. Gastrostomy can be placed percutaneously or surgically, and jejunostomy requires surgical placement. For patients with intact upper GIT, the administration of the enteral diet via gastrostomy is preferred; otherwise jejunostomy is used ${ }^{4,8}$.

Enteral nutrition occurs via the administration of polymeric or oligomeric liquid formulas, which contain all the essential macronutrients, except for fibers, which are only present in special formulas. In relation to vitamins and minerals, they generally meet the daily needs recommended by the Recommended Dietary Allowance (RDA) ${ }^{1,2}$. A wide variety of enteral feeding products are currently commercially available, therefore the assessment of the suitability and efficacy of the formulations should be carefully considered. It is also essential to take into account the sources of the substrates present in each diet while choosing the formulation, considering that some patients require specialized formulas according to their pathology ${ }^{1}$.

The formulations of industrialized diets can be basically of two types of system: closed and open. In the first type, the diets are ready for use and are already packaged in their own containers, directly coupled to equipment. In the second case, the diets need manipulation or previous packaging for later administration ${ }^{3}$.

Some other physical characteristics of the diets should also be taken into consideration when choosing the formula, such as: osmolarity, digestibility, macronutrient distribution, and caloric density of the product $^{5}$. Enteral products may be further classified according to their caloric density in normocaloric, in which the formulations may be between $1.0-1.2 \mathrm{kcal} / \mathrm{ml}$ or hypercaloric, in which the density should be above $1.2 \mathrm{kcal} / \mathrm{ml}$, currently being around $1.5 \mathrm{kcal} / \mathrm{ml}$.

The type of diet or enteral product offered should be chosen based on the individual characteristics of each patient, and according to the needs generated by the pathologies from which they are affected ${ }^{9,10}$.

Patients who are at risk of malnutrition are potential candidates for enteral nutritional therapy, since it allows for a more effective control of the patient's nutrition. However, it is important to emphasize that the use of enteral nutrition should be slowly initiated in malnourished patients or in those who had long fasting periods, to avoid consequences such as the refeeding syndrome. Other patients requiring care are those with sepsis and/or multiple organ dysfunction syndrome (MODS), who are at high risk of complications and should be carefully examined ${ }^{11,12}$. However, it is worth mentioning that the state of malnutrition is a direct cause of longer hospital stay, increase in the number of infectious and noninfectious complications, lower bed turnover rates, and a higher cost per hospitalized patient. These associated factors lead to higher health expenses ${ }^{13,14}$.

Enteral nutritional therapy is, therefore, a great resource available to prevent and to try to recover from malnutrition, a problem so commonly observed in hospitals worldwide. According to data from the Brazilian Inquiry on Hospital Nutritional Evaluation/Inquérito Brasileiro de Avaliação Nutricional Hospitalar (IBRANUTRI), a multicenter study involving 23 hospitals from different regions of Brazil conducted in 1996, half of the patients hospitalized in Brazilian public hospitals are malnourished ${ }^{10}$. This study also showed that patients have been neglected in relation to nutritional therapy, since $85 \%$ of the patients had no reference about their nutritional status, and that about $10 \%$ of the total number of patients received enteral nutrition ${ }^{10}$.

According to the latest guidelines published by the British Society of Gastroenterology (BSG), malnourished patients are hospitalized for a period $50 \%$ longer than those who are adequately nourished, which, in addition to bringing more risks to the patient, also entails more hospital costs ${ }^{8}$.

In order to reestablish the health of the hospitalized individuals, it is essential that they receive adequate nutrition, since well-nourished individuals have a better response to clinical treatment ${ }^{12}$. Several studies show that the caloric-protein needs of hospitalized patients are rarely reached in the supply of enteral nutrition, routinely reaching $70-80 \%$ of their needs. This issue may be related to the high caloric-protein malnutrition statistics pointed out by IBRANUTR $\left.\right|^{9,12,15}$.

Numerous factors are identified as determinants of this inadequate nutritional supply, with the most frequent including: physiological factors of gastrointestinal intolerance, such as vomiting and diarrhea; mechanical complications; and fasting for surgeries and exams. Besides these factors, it is known that the hospitalized patient is assisted by a multiprofessional team that seeks their recovery through numerous therapies and care, and it is in this context that the enteral diet is often not adequately supplied, given the need for a pause in the administration of the diet, such as, for example, in physiotherapy sessions and in the administration of medications, among other factors, and therefore, the total volume prescribed often ends up not being reached ${ }^{16-18}$.

This way, it is known that the knowledge about the functioning of the enteral nutrition routines is extremely important, as well as about the nutritional supply that the hospitalized patient actually receives. This will allow the detection of failures and the possibility of implementing measures to optimize the use of enteral therapy.

The objective of this study is to compare the caloric intake prescribed and received in hospitalized patients under enteral nutritional therapy. 


\section{METHODS}

A descriptive study was conducted based on secondary data collected by the Multidisciplinary Nutritional Therapy Team (EMTN) of Hospital São Lucas (HSL) from PUCRS. The study included 43 adult patients over the age of 18 years admitted to the Intensive Care (ICU) and Emergency Units, from July to September 2004, who received enteral nutrition for more than two consecutive days, including industrialized products of the open or closed systems via the nasogastric or nasoenteral route, during the entire period of hospitalization in which the patient was fed exclusively via enteral nutrition.

As a parameter to verify the caloric intake received by the patient we used the maximum value offered during enteral nutritional therapy, since the beginning of the therapy occurs gradually, increasing the volume of diet as tolerated by the patients. This maximum intake received was compared to the nutritional needs of each patient, calculated by the Harris - Benedict formula (1919) to stipulate Basal Energy Expenditure (BEE) according to gender: for males $B E E=66+(13.7 \times W)+(5 \times H)-(6.8 \times A)$; and for females: $B E E=655+(9.6 \times W)+(1.7 \times H)-(4.7 \times A)$, being $\mathrm{W}=$ weight, $\mathrm{H}=$ height, and $\mathrm{A}=$ age. . Later, the Total Energy Expenditure (TEE) of patients was calculated using the formula: $T E E=B E E \times I F$, being IF = injury factor ${ }^{3}$.

Based on the information collected on height and weight, the Body Mass Index (BMI) of the patients was calculated using the formula: $\mathrm{BMI}=$ Weight $/ \mathrm{Height}^{2}$ and classified according to the World Health Organization (1995-1997) as: BMI $<16 \mathrm{~kg} / \mathrm{m}^{2}$ thinness grade III, between $16.0-16.9 \mathrm{~kg} / \mathrm{m}^{2}$ thinness grade II, between $17.0-18.4 \mathrm{~kg} / \mathrm{m}^{2}$ thinness grade I, between $18.5-24.9 \mathrm{~kg} / \mathrm{m}^{2}$ adequate or eutrophic, between $25.0-29.9 \mathrm{~kg} / \mathrm{m}^{2}$ pre-obese, between $30.0-34.9 \mathrm{Kg} / \mathrm{m}^{2}$ obesity grade I; between $35-39.9 \mathrm{~kg} / \mathrm{m}^{2}$ obesity grade $\mathrm{II}$; and $\geq 40 \mathrm{~kg} / \mathrm{m}^{2}$ obesity grade $\mathrm{III}^{4,12}$. This was the index used to classify the patients' nutritional status.

It is the hospital's routine to administer the diet along six periods of time, and the total volume is divided between these schedules if the type of diet chosen for the patient is open system. If the patient uses a closed system, the packs pertaining to the daily amount are supplied to the nursing station in the first hour of delivery of the day's food supply. The data regarding the diet plan were collected from the standard enteral therapy forms during the period in which the patient used enteral nutrition, including type of product and formula used, as well as volume administered. As a reference for the caloric value offered we used the greatest intake reached during the use of enteral nutrition.

The present study contemplated the ethical considerations necessary for conducting research in humans and started only after the approval of the institution's Research Ethics Committee under number 548672006. A descriptive analysis of the data was performed, and the results were expressed as mean \pm standard deviation $(\mathrm{M} \pm \mathrm{SD})$ and percentages.

\section{RESULTS}

The study analyzed a total of 43 patients $(24 \mathrm{M} / 19 \mathrm{~F}$, $61 \pm 17$ years), hospitalized both in the ICU and in the Emergency Unit, (38\% and $62 \%$ respectively), who received enteral nutrition as an exclusive feeding route during the hospitalization period. Regarding the nutritional status distribution, we observed that most patients presented some kind of malnutrition/thinness (Figure 1).

It was observed that most assessed patients received open-system formulas $(86 \%)$ rather than closed-system (24\%); that is, a large part of the group uses formulations prepared and manipulated

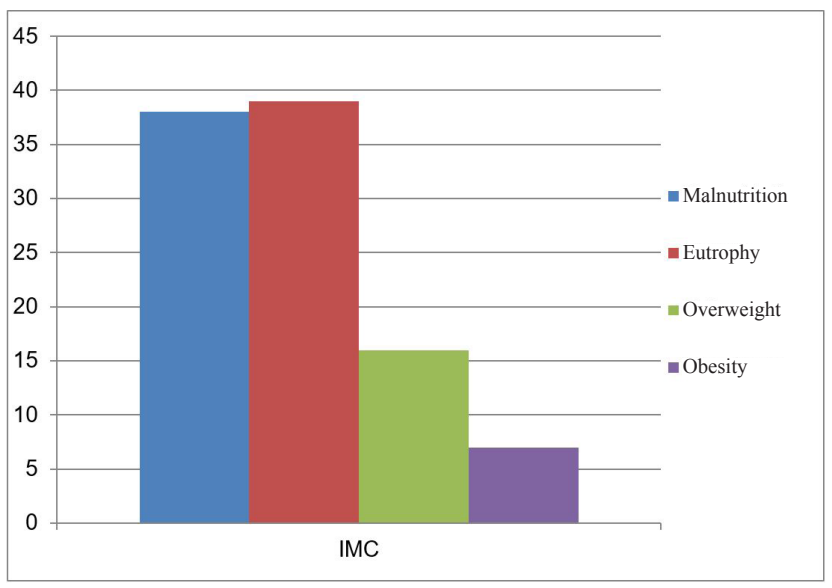

Figure 1: Nutritional status of patients using enteral nutrition according to the imc. 
in the hospital dietetic department. Regarding the formulations used in these patients, we observed that the hospital's standard formula, which is normocaloric and normoproteic, was the most used (approximately $40 \%$ ), followed by the hypercaloric high-protein modulated standard formula (approximately $30 \%$ ), and $20 \%$ of the other formulas included non-protein or with altered protein content, hyperlipidic, and normocaloric and hypercaloric closed-system formulas.

Regarding the caloric intake, it was observed that approximately $94 \%(S D=18.1 \%)$ of the needs were reached, with an average of $1,767 \pm 2,71 \mathrm{kcal} /$ day as well as estimated caloric needs averaging $1,875 \pm 321 \mathrm{kcal} /$ day. Of the total sample, only $4(9.30 \%)$ patients received less than half of what should be administered, and $35(81.39 \%)$ patients received an amount corresponding to a minimum of $90 \%$ of their daily needs.

\section{DISCUSSION}

Enteral nutritional therapy is indicated when there is a risk of malnutrition, i.e., when oral intake is inadequate to provide from two-thirds to three-quarters of daily nutritional needs, but it is also necessary that the digestive tract is fully or partially functioning. Exceptions such as cases of total intestinal obstruction and paralytic ileus, for example, should be evaluated ${ }^{3,4}$.

Malnutrition is an extremely unfavorable factor for clinical evolution, since its deleterious consequences affects all organic systems, making the malnourished individual more susceptible to complications, thus increasing morbidity and mortality, hospitalization time, and hospital costs ${ }^{12,17}$.

In the present study, it was observed that $38 \%$ of the patients were in malnutrition/ thinness, and were critically ill patients, who for various reasons, such as an acute trauma or an infection, for example, were in a hypercatabolic state, which is associated with a loss of body weight and immune function, consequently compromising the evolution of their recovery, and about $9 \%$ were in a state of malnutrition, which indicates that approximately $46 \%$ of the total had some degree of malnutrition. According to the results by IBRANUTRI, around $48 \%$ of hospitalized patients are malnourished, and of these, more than $12.6 \%$ present severe malnutrition ${ }^{13}$. These numbers are relatively lower than those obtained by the Latin American Study of Nutrition and Health/Estudo Latino-Americano de Nutrição (ELAN), a study conducted in Latin American countries, similar to IBRANUTRI, which observed that $50 \%$ of patients presented some sort of malnutrition, being approximately $13 \%$ severe malnutrition and $38 \%$ mild malnutrition ${ }^{19}$. Thus, it can be observed that the data obtained in the present study showed a great similarity in relation to the other studies, showing that, although four years have passed since the IBRANUTRI study, the condition of hospitalized patients remain unsatisfactory. The results of IBRANUTRI and ELAN reveal that nutritional therapy has not been effectively applied, which contributes to the increase in the prevalence of hospital malnutrition ${ }^{11,13,19,20}$.

Regarding the mean age of the hospitalized patients analyzed (61 \pm 17 years), the elderly were predominant, what is consistent with other studies involving patients in enteral nutritional therapy, which similarly found the mean age of 55 to 67 years. It is worth noting that the increased prevalence of elderly people who are in malnutrition status is also observed in other studies ${ }^{12,21,22}$.

Since the analyzed patients were hospitalized in two hospital units characterized by severe patients, Emergency Unit and ICU, it is emphasized that the hypermetabolic patient frequently stays hospitalized for long periods, and the introduction of adequate enteral nutritional therapy may attenuate the metabolic response to trauma, decreasing catabolism, and thus favoring recovery and avoiding and/or alleviating malnutrition ${ }^{7,8}$.

The study conducted by De Jonghe observed that enteral supply or prescription covered about $78 \%$ of the caloric needs of the patients, and what the patient actually received, controlling all intercurrences, was only $71 \%$ of this total ${ }^{13}$. In the present study, it was observed that the caloric intake offered was adequate, reaching $94 \%$ of the energy needs of the evaluated patients. It was also observed that the total caloric offer was on average 1,767 $\pm 271 \mathrm{kcal} /$ day (94\% TEE), while the estimated caloric requirements were on average $1,875 \pm 321 \mathrm{kcal} /$ day.

In a study similar to the present one, Abernathy ${ }^{23}$ et al. evaluated 35 adult patients receiving exclusive enteral nutrition and found that the effective intake was $1,095 \pm 41 \mathrm{kcal}(61 \%$ of TEE), and prescriptions covered about $75 \%$ of the patients' intake needs, numbers well below those found in the present study. In another study, Spain et al., after establishing infusion protocols, observed that the calories actually received went from $52 \%$ to $68 \%$ of TEE and dietary prescription went from $66 \%$ to $82 \%$ of TEE $^{24}$. In another study, McClave ${ }^{11}$ et al. evaluated the supply of enteral nutrition only in ICU patients and found that they received an average of $52 \%$ of TEE, and that adequacy was approximately $78 \%$ in relation to the prescribed volume, significantly lower than the one found in the present study. Thus, according to the literature, the caloric intake offered to hospitalized patients in general is insufficient, which may be compromising the individuals' nutritional status and affecting and/or aggravating their prognosis ${ }^{9-11,23}$. 
According to Abernathy et al., among the most frequent causes of diet interruption stand out factors such as mechanical complications, gastrointestinal intolerance, and preoperative fasting. However, the present study did not investigate the amount of diet actually administered to the patients, but rather the nutritional prescription made ${ }^{23}$. It is known that numerous factors can lead to interruptions in dietary supply, such as: fasting time for exams, gastric stasis volume, and a high degree of diarrhea, which would promote non-compliance with the prescribed dietary therapy.

Thus, it is essential that the patients effectively receive the calories they need, since several factors related to the underlying pathologies may favor malnutrition and contribute to the depletion condition, such as: anorexia and early satiety, nausea or vomiting, malabsorption due to some pathologies that may lead to changes in energy and protein metabolism, as well as changes caused by medications ${ }^{10,11,17}$.

As previously mentioned, in the present study we considered the nutritional prescription made for each patient to assess the caloric intake received. In the study conducted by Spain, who also considered this type of prescription, it was observed that after the institution of infusion protocols, the calories effectively received increased from $52 \%$ to $68 \%$ of TEE, and dietary prescription increased from $66 \%$ to $82 \%$ of the TEE, that is, the establishment of protocols increased the adequacy of the supply in relation to needs ${ }^{24}$.

\section{CONCLUSION}

It is necessary that further studies be conducted aimed at controlling the factors that limit the supply of the total dietary intake so that we can assess the volume that the patient actually receives. The creation of nutrition support protocols is paramount to guide professionals in the prescription of enteral nutritional therapy, aiming to improve the nutritional supply offered to hospitalized patients. These protocols would control the possible mechanisms that hinder the adequate caloric intake and would allow optimizing the nutritional therapy results, translated by the improvement of the nutritional status of the patients.

\section{REFERENCES}

1. ASPEN Board of Directors and the Clinical Guidelines Task Force. Guidelines for the use of parenteral and enteral nutrition in adult and pediatric patients. JPEN J Parenter Enteral Nutr. 2002;26(1 Suppl 1):1SA138SA.

2. Gottschlich MM, Fuhrman MP, Hammond KA, Holcombe BJ, editors. The science and pratic of nutrition support: a case-basead core curriculum. Dubuque: Kendall Hunt Pub Co; 2000.

3. Cuppari L. Guia de nutrição clínica no adulto. São Paulo: Manole; 2002.

4. Waitzberg DL. Nutrição oral enteral e parenteral na prática clínica. 3. ed. Rio de Janeiro: Atheneu; 2000.

5. Buchman AL. Manual de suporte nutricional. São Paulo: Manole; 1998.

6. Mahan LK, Escott-Stump S, Raymond JL. Krause: alimentos, nutrição e dietoterapia. 9. ed. São Paulo: Roca; 1998.

7. Zaloga GP. Early enteral nutritional support improves outcome: hypothesis or fact? Crit Care Med.
1999;27(2):259-61. PMid:10075044. http://dx.doi.org/10.1097/00003246199902000-00024.

8. Pinilla JC, Samphire J, Arnold C, Liu L, Thiessen B. Comparison of gastrointestinal tolerance to two enteral feeding protocols in critically ill patients: a prospective, randomized controlled trial. JPEN J Parenter Enteral Nutr. 2001;25(2):81-6. PMid:11284474. http://dx.doi.org/10.11 77/014860710102500281.

9. Jolliet $P$, Pichard $C$, Biolo $G$, Chioléro R, Grimble G, Leverve X, et al, Working Group on Nutrition and Metabolism, European Society of Intensive Care Medicine. Enteral nutrition in intensive care patients: a practical approach. Intensive Care Med. 1998;24(8):848-59. PMid:9757932. http://dx.doi. org/10.1007/s001340050677.

10. Adam S, Batson S. A study of problems associated with the delivery of enteral feed in critically ill patients in five ICUs in the UK. Intensive Care Med. 1997;23(3):2616. PMid:9083227. http://dx.doi. org/10.1007/s001340050326.
11. McClave SA, Sexton LK, Spain DA, Adams JL, Owens NA, Sullins $M B$, et al. Enteral tube feeding in the intensive care unit: factors impeding adequate delivery. Crit Care Med. 1999;27(7):1252-6. PMid:10446815. http://dx.doi.org/10.1097/00003246199907000-00003.

12. Edington J, Kon P, Martyn CN. Prevalence of malnutrition in patients in general practice. Clin Nutr. 1996;15(2):60-3. PMid:16843999. http://dx.doi.org/10.1016/S02615614(96)80020-3.

13. Waitzberg DL, Caiaffa WT, Correia MI. Hospital malnutrition: the Brazilian national survey (IBRANUTRI): a study of 4000 patients. Nutrition. 2001;17(7-8):573-80. PMid:11448575. http://dx.doi.org/10.1016/S08999007(01)00573-1.

14. MacLaren R. Intolerance to intragastric enteral nutrition in critically ill patients: complications and management. Pharmacotherapy. 2000;20(12):1486-98. PMid:11130221. http://dx.doi.org/10.1592/ phco.20.19.1486.34853. 
15. De Jonghe B, Appere-De-Vechi C, Fournier M, Tran B, Merrer J, Melchior JC, et al. A prospective survey of nutritional support practices in intensive care unit patients: what is prescribed? What is delivered? Crit Care Med. 2001;29(1):8-12. PMid:11176150. http://dx.doi. org/10.1097/00003246-20010100000002.

16. Braunschweig CL, Levy $P$, Sheean PM, Wang X. Enteral compared with parenteral nutrition: a meta-analysis. Am J Clin Nutr. 2001;74(4):534-42. PMid:11566654.

17. Mentec H, Dupont $\mathrm{H}$, Bocchetti M, Cani P, Ponche F, Bleichner G. Upper digestive intolerance during enteral nutrition in critically ill patients: frequency, risk, factors, and complications. Crit Care Med. 2001;29(10):1955-61. PMid:11588461. http://dx.doi.org/10.1097/00003246200110000-00018.
18. Silva AF, Campos DJ, Souza MH, Shieferdecker ME. Capacidade da terapia nutricional enteral em fornecer as necessidades calórico-proteicas de pacientes hospitaizados. Rev Bras Nutr Clin. 2003;18:113-8.

19. Correia MI, Campos AC, ELAN Cooperative Study. Prevalence of hospital malnutrition in Latin America: the multicenter ELAN study. Nutrition. 2003;19(10):823-5. PMid:14559314. http://dx.doi.org/10.1016/S08999007(03)00168-0.

20. Montejo JC, The Nutritional and Metabolic Working Group of the Spanish Society of Intensive Care Medicine and Coronary Units. Enteral nutritionrelated gastrointestinal complications in critically ill patients: a multicenter study. The Nutritional and Metabolic Working Group of the Spanish Society of Intensive Care Medicine and Coronary Units. Crit Care Med. 1999;27(8):144753. PMid:10470748. http://dx.doi. org/10.1097/00003246-19990800000006.
21. Lipschitz DA. Screening for nutritional status in the elderly. Prim Care. 1994;21(1):55-67. PMid:8197257.

22. Couto JC, Bento A, Couto CM, Silva $B C$, Oliveira IA. Nutrição enteral em terapia intensiva: o paciente recebe o que prescrevemos? Rev Bras Nutr Clin. 2002;17:43-6.

23. Abernathy GB, Heizer WD, Holcombe BJ, Raasch RH, Schlegel KE, Hak LJ. Efficacy of tube feeding in supplying energy requirements of hospitalized patients. JPEN J Parenter Enteral Nutr. 1989;13(4):387-91. PMid:2506375. http://dx.doi.org/10.11 77/0148607189013004387.

24. Spain DA, McClave SA, Sexton LK, Adams JL, Blanford BS, Sullins $\mathrm{ME}$, et al. Infusion protocol improves delivery of enteral tube feeding in the critical care unit. JPEN J Parenter Enteral Nutr. 1999;23(5):288-92. PMid:10485441. http://dx.doi.org/10.1 177/0148607199023005288.

Received: feb 012017 Accepted: jul 032017 